\title{
QUEEN'S
UNIVERSITY
BELFAST
}

\section{The Computational Post Buckling Analysis Of Fuselage Stiffened Panels Loaded In Shear}

Murphy, A., Price, M., Lynch, C., \& Gibson, A. (2005). The Computational Post Buckling Analysis Of Fuselage Stiffened Panels Loaded In Shear. Thin-Walled Structures, 43 (9)(9), 1455-1474.

https://doi.org/10.1016/j.tws.2005.03.010

\section{Published in:}

Thin-Walled Structures

\section{Document Version:}

Peer reviewed version

Queen's University Belfast - Research Portal:

Link to publication record in Queen's University Belfast Research Portal

\section{General rights}

Copyright for the publications made accessible via the Queen's University Belfast Research Portal is retained by the author(s) and / or other copyright owners and it is a condition of accessing these publications that users recognise and abide by the legal requirements associated with these rights.

Take down policy

The Research Portal is Queen's institutional repository that provides access to Queen's research output. Every effort has been made to ensure that content in the Research Portal does not infringe any person's rights, or applicable UK laws. If you discover content in the Research Portal that you believe breaches copyright or violates any law, please contact openaccess@qub.ac.uk. 


\title{
THE COMPUTATIONAL POST BUCKLING ANALYSIS OF FUSELAGE STIFFENED PANELS LOADED IN SHEAR.
}

\author{
A. Murphy ${ }^{+}$, M. Price, C. Lynch ${ }^{*}$, A. Gibson \\ School of Aeronautical Engineering, Queen's University Belfast, Belfast, N. Ireland \\ * Timoney Group, Gibbstown, Navan, Co. Meath, Ireland \\ +Corresponding author: Email: a.murphy@qub.ac.uk Fax: +44 (028) 90975576
}

\begin{abstract}
Fuselage panels are commonly fabricated as skin-stringer constructions, which are permitted to locally buckle under normal flight loads. The current analysis methodologies used to determine the post buckling response behaviour of stiffened panels relies on applying simplifying assumptions with semi-empirical / empirical data. Using the Finite Element method and employing non-linear material and geometric analysis procedures it is possible to model the post buckling behaviour of stiffened panels without having to place the same emphases on simplifying assumptions or empirical data. Previous work has demonstrated that using a commercial implicit code, the Finite Element method can be used successfully to model the post buckling behaviour of flat riveted panels subjected to uniform axial compression. This paper expands the compression modelling procedures to flat riveted panels subjected to uniform shear loading, investigating element, mesh, idealisation and material modelling selection, with results validated against mechanical tests. The work has generated a series of guidelines for the non-linear computational analysis of flat riveted panels subjected to uniform shear loading, highlighting subtle but important differences between shear and compression modelling requirements.
\end{abstract}

Keywords: Fuselage buckling analysis, Post buckling analysis, Non-linear Finite Element modelling, Stiffened panel shear testing. 


\section{Introduction}

\subsection{Background}

Fuselage structure consists of longitudinal stiffeners (stringers and longerons), which run the length of the fuselage, distributed transverse elements (frames and bulkheads), which stabilise the structure from within, and the fuselage external skin. The stiffened panel structure is designed to cope with a variety of loading conditions including shear loading. Local skin shear buckling is waving of the fuselage skin between the stringers and frames into visible folds. The structure will not fail with local skin buckling, as the stringers will continue to carry increased load. In addition the skin is still capable of carrying shear load through tension-loaded bands of material located between the buckles. This condition is referred to as a state of incomplete diagonal tension [1] and forms the basis of the conventional post-buckling analysis.

There are well established analysis procedures based on semi-empirical equations which are widely used in industry. However current trends in developments of materials and joining processes as well as geometric configurations have pushed towards the limits of applicability of these methods. Although finite element (FE) methods have been successfully used to model buckling behaviour the time and expertise required means that they are used only sparingly for these problems despite their promise for providing a means of both understanding the behaviour of these structures and also for enabling trade-off studies to be rapidly and reliably carried out between competing configurations and manufacturing processes.

In order to facilitate more widespread and consistent use of FE for these problems this work attempts to address issues around idealisations, material modelling and element selection to provide a consistent and reliable approach. The methods are of course validated. The next section reviews key elements of conventional analysis before looking at FE methods and testing. 


\subsection{Conventional Fuselage Panel Design}

The post buckling behaviour of stiffened shear panels and tension fields was first considered in the late nineteenth-century by Wilson [2]. Wilson's ideas were added to by Rode in 1916 with an early mathematical formulation of a tension field, Basler [3]. In the mid twentieth century Wagner [4] developed the 'pure diagonal tension' theory, which Kuhn [5] twenty years later extended to the 'incomplete diagonal tension' theory having carried out an extensive experimental programme [6]. Kuhn expanded the beam web analysis to flat fuselage panels loaded in shear and compression and, to curved panels loaded in shear and compression. Kuhn's approach, based on 'incomplete diagonal tension' theory is still the basis of today's aerospace shear post buckling analysis procedures, documented in Bruhn [7].

The engineering stress theory of incomplete diagonal tension is based on the assumption that the nominal skin shear stress, $\tau$, comprises two components. A true-shear component, $\tau_{\mathrm{s}}$, and a diagonal-tension component, $\tau_{\mathrm{dt}}$. The nominal skin shear stress is related to the true-shear component via the diagonal-tension factor, $\mathrm{k}$, equation (1). The diagonal-tension stress component is related to the nominal skin shear stress again via $\mathrm{k}$, the diagonal-tension factor, equation (2).

$$
\begin{aligned}
\tau_{\mathrm{s}} & =(1-\mathrm{k}) \cdot \tau \\
\tau_{\mathrm{dt}} & =\mathrm{k} \cdot \tau
\end{aligned}
$$

At a specific load level, $\mathrm{k}$, the diagonal-tension factor is given by the empirical expression:

$$
\mathrm{k}=\tanh \left(0.5 \cdot \log \frac{\tau}{\tau_{\mathrm{cr}}}\right)
$$


where $\tau_{\mathrm{cr}}$ is the local skin shear buckling stress. A diagonal-tension factor of zero characterises an unbuckled skin panel and a diagonal-tension factor of one characterises a skin panel in pure diagonal-tension.

For typical aircraft fuselage panel design, the dominant form of stiffened post buckling failure under shear loading is forced crippling. This occurs when the shear buckles in the panel skin force the attached stiffener flanges to deform out-of-plane. The deformations in the stiffener flanges in turn induce deformations of the stiffener outstanding elements. These stiffener deformations accelerate the onset of column crippling due to compression loading. Forced crippling is of a local nature, therefore failure is assumed to depend on a peak value of stress in the stringer rather than an average stringer stress.

Local shear buckling of a panel skin bay is evaluated using the simple plate buckling equation, equation (4), where $\mathrm{k}_{\mathrm{s}}$ is the shear plate buckling coefficient, Bruhn [7]. The width of the plate, $\mathrm{b}$, is defined as the distance between stringer rivet lines, and the length of the plate, $a$, is defined as the distance between frame rivet lines, Figure 1. Finally, within riveted fuselage structure the plate is assumed to be simply-supported along all four edges.

$$
\tau_{\mathrm{cr}}=\frac{\pi^{2} \cdot \mathrm{k}_{\mathrm{s}} \cdot \mathrm{E}_{\mathrm{T}}}{12\left(1-\mathrm{v}^{2}\right)} \cdot\left(\frac{\mathrm{t}}{\mathrm{b}}\right)^{2}
$$

The post local skin buckling, forced crippling panel analysis, is based on empirical data generated at NACA ${ }^{1}$ and documented by Kuhn [6]. The experimental data on which the empirical methods were developed exhibited 'a scatter band of $\pm 20 \%$; the analysis formulas are based on the lower edge of the scatter band'. The forced crippling stiffener failure stress, $\sigma_{\mathrm{fd} \_c c}$, is related to diagonaltension factor, $\mathrm{k}$, the thickness of the stiffener attached flange, $\mathrm{t}_{\text {flange, }}$, the skin thickness, $\mathrm{t}$, and the

\footnotetext{
${ }^{1}$ NACA (National Advisory Committee Aeronautics) was the precursor to NASA (National Aeronautics and Space Administration).
} 
stiffener material properties. Given the skin and stiffener material properties (compressive yield stress $\sigma_{\mathrm{cy}}$, Young's Modulus E, equations (5), (6) and (7) allow the empirical evaluation of stiffener forced crippling stress:

$$
\sigma_{\text {fd_cc }_{-}}=\mathrm{N} \times \mathrm{C}
$$

where

$$
\begin{aligned}
& \mathrm{N}=30000 \cdot \mathrm{k}^{\frac{2}{3}} \cdot\left(\frac{\mathrm{t}_{\text {flange }}}{\mathrm{t}}\right)^{\frac{1}{3}} \\
& \mathrm{C}=\frac{\sigma_{\mathrm{cy}} \times 10^{-5}}{5.88 \cdot\left(\frac{\sigma_{\mathrm{cy}}}{\mathrm{E}}+0.002\right)^{\frac{1}{2}}}
\end{aligned}
$$

\subsection{Stiffened panel shear testing}

There are numerous shear panel test rig configurations within the literature $[6,8-10,14-15]$, with the simplest and most common being the picture frame. The rig is as simple as the name suggests, a square or rectangular specimen is assembled with four rigid side members, which are pin jointed at their ends. The rigid frames form a mechanism that transforms applied axial rig load into specimen shear loads. Theoretically, to produce uniform shear the frame members should be infinitely stiff, however in practice several orders of magnitude greater than the specimen in-plane stiffness is sufficient $[8,9]$. In addition to rig stiffness, alignment of picture frame corner-pins is of great importance in applying uniform specimen shear. Farley [9] demonstrated that specimen stress distribution was uniform with negligible normal stresses when rig pins are located at specimen corners. As the pin locations are moved away from specimen corners points the resulting specimen applied shear stress reduces in quantity. 
The major disadvantage of picture frames for panel post buckling analysis is the restraint on specimen end-shortening. Due to the required high axial and bending stiffness of frame members to apply uniform shear stress, specimen diagonal tension loads are almost entirely absorbed by the specimen frames and not the specimen stiffeners [8]. Despite this disadvantage a number of researchers $[8,10]$ have used picture frame for post buckling analysis work. Sobel [10] attached the shear specimens to the picture frame rig via breather joints, Fig. 2, which were designed to force the diagonal tension load in the skin to be reacted by the stiffener, rather than the test frame. The breather joints used at the compliant edges of the test frame, normal to the direction of specimen stiffener, permitted specimen longitudinal end-shortening. However, the standard rigid joints used on the parallel edges to the stiffener act to constrain both longitudinal and lateral specimen endshortening.

Wagner beams are common beam type shear tests, in which the shear webs are loaded via beam lateral loading. Considering the design of civil structural beams, buckling of shear webs is a common design criteria and therefore a considerable amount of work has been undertaken by civil researchers into plate girder shear web buckling [11]. Kuhn's [5] empirical diagonal tension analysis methodologies, which are the basis of current fuselage panel post buckled shear analysis, were formulated, based on experimental data obtained primarily from NACA tests on beams $[6,12-$ 13]. With the standard Wagner beam set-up the beam flanges, which represent panel frames, require a high level of stiffness to transfer the shear loading to the web, representing the panel skin. Typical fuselage frames require reinforcing to perform this loading task. Reinforcing the frame structure alters the web boundary conditions and therefore influences the buckling behaviour.

Considering the limitations of the standard picture frame and Wagner beam test for post buckling studies, Rothwell $[14,15]$ utilised a rail shear experimental set-up for the study of the buckling failure of stiffened shear webs. Rothwell's experimental set-up is illustrated in Fig. 3, the web specimens were loaded via massive longitudinal loading members, which were hinged to each other on both sides of the specimen. As with Sobel's [10] experiments the specimens were attached 
to the loading members via flexible breather joint, Fig. 3, design to allow specimen end shortening while providing simply supported edge conditions. The specimen edge skins were supported with pivoted supports, Fig. 3. Rothwell [14] notes that the rig did not permit complete failure of the stiffened web due to the necessary specimen edge supports. However, a number of central stiffeners for each test, 'showed clear and rapid visible evidence of failure'.

Finally, a barrel test is the most expensive but most representative method of examining the post buckling behaviour of stiffened barrel structures. The circular cylinder specimen is simply loaded in torsion, therefore generating shearing panel loads. Due to the high costs of manufacturing barrels and testing them to failure, few research tests are preformed [6]. The majority of barrel tests are therefore undertaken by aircraft manufacturers, for certification purposes, generating few publicly available reports containing technical details.

\subsection{Reducing Analysis Reliant on Empirical Design Formulae}

Previous work $[16,17]$ has demonstrated that using a commercial implicit code, the Finite Element method can be used successfully to model the post buckling behaviour of flat riveted panels subjected to uniform axial compression. The question to be answered herein is then; can the developed modelling procedures be expanded to cover flat riveted panels subjected to uniform shear loading?

\section{Computational Analysis}

\subsection{Idealisation}

For any computational analysis the 'real' structure must be idealised since the detail required to capture all behaviour exceeds the current computational capabilities. The choice of idealisation philosophy is highly dependent on the anticipated failure behaviour of the structure, as the model idealisation must accurately simulate this behaviour. Aircraft stiffened panel structures are 
susceptible to both local skin and stiffener buckling behaviour and global stiffener buckling behaviour, both possible involving elastic and plastic material behaviour.

Airframe models intended for use in the study of structural load paths and magnitudes are not concerned with failure modes, and therefore, the so called conventional idealisation philosophy for stiffened panel structures tends to model the skin structure with shells and the stiffener structures with beams, Figure 4. This level of idealisation will accurately and efficiently represent the structure's linear stiffness but will fail to capture stiffener local cross-section translation and rotations and therefore fail to accurately model non-linear buckling and post buckling behaviour [17-19]. In order to predict the collapse behaviour the cross-section must be modelled in detail [18]. The idealisation philosophy developed and validated for compression loaded panels in the previous article [16] modelled the panel skin, stringers and frames as a system of shell elements, with the addition of beam elements to represent stringer bulbs, Figure 5. In addition, the initial compression based study considered a number of different idealisations of skin-rivet-stringer interface, and determined that riveted panels are not accurately represented if modelled as integral structures. The work concluded that panel rivets must be modelled as discrete connections, with separation of the components allowed to occur away from the rivet locations. Based on these findings the shear loaded panels will also be modelled as an assembly of 3D shells. The skin, stringer and frame webs and flanges will be represented by shell elements, the stringer bulbs will be represented by beam elements and rigid links elements will simulate the panel rivets.

\subsection{Element Selection}

For any Finite Element analysis a mesh convergence study must be preformed to determine the required model element density. For buckling analysis the aim of the study is the definition of the minimum element mesh required to accurately represent buckle waves. The previous compression based study considered element and mesh selection procedures. The modelling methods were validated against a series of panel experimental tests. The compression based study produced a series of analysis guidelines with respect to the required model element density, however the 
guidelines are not fully generic and were refined for the analysis of flat riveted panels subjected to uniform axial compression. Moreover, the study highlighted that quadratic shell elements provide the most efficient and accurate solution for small sub-component models, but for larger panel structures with multiple stiffeners linear shells provide a more robust solution and with sufficient mesh refinement will lead to accurate failure predictions. The compression analysis concluded that it is necessary to carry out element and mesh selection studies relevant to the class of structure being studied.

The previous investigation determined the most suitable elements for compression panel buckling analysis was ABAQUS ${ }^{\mathrm{TM}}$ element S8R5, a second-order curved quadrilateral 8-noded thin shell element [20]. Based on this work and considering both first and second-order elements a mesh convergence study of the buckling behaviour of a simply supported rectangular plate under uniform shear load was undertaken. The performance of five ABAQUS ${ }^{\mathrm{TM}}$ elements were assessed based on convergence with corresponding theoretical behaviour [21] with increasing mesh densities. Based on this analysis two element types were selected for full panel analysis. The first-order curved quadrilateral 4-noded finite strain general purpose shell element, S4R [20] and the second-order curved quadrilateral 8-noded thick shell element, S8R [20].

\subsection{Material Modelling}

Clearly not only must the geometric buckling behaviour be accurately modelled, but the material behaviour for the skin, stringer and frames must also be appropriately represented. Material properties obtained from coupon tests are used for all Finite Element analysis. Material test coupons were taken from the same material batches as the components from which the test validation specimens were manufactured. Material curves were incorporated into the Finite Element analysis models using the 'classical metal plasticity' constitutive theory available within the ABAQUS material library [20]. Since a shear loaded panel within its post buckling range will exhibit regions straining in tension and regions straining in compression both material data types are considered within the specimen analysis study. 


\subsection{Solution Procedure}

The initial compression based study considered suitable solution procedures for buckling collapse analysis, benchmarking the procedure against a series of panel experimental tests. The study concluded that, with appropriate level of artificial damping, a damped Newton-Raphson procedure may be used to predict post buckling and collapse behaviour of large panels.

\subsection{Initial imperfection Modelling}

Based on theory [22] and clearly demonstrated in the literature [23-25], the modelling of initial geometric imperfections is of great importance when evaluating initial skin buckling behaviour. In addition, failure behaviour may be affected by geometric imperfections if the imperfections are 'large' and span the entire structure [16]. Riveted panel geometric manufacturing imperfections occur as a result of residual stresses generated during the specimen riveting process. Lynch [23] demonstrated a high degree of sensitivity to residual stresses when evaluating local skin buckling. The modelling of both geometric imperfections and stress imperfections (i.e. residual stresses) must be considered when evaluating the accurate of any predicted buckling behaviour.

\section{Validation}

\subsection{Test Rig Design}

This section introduces experimental work carried out to validate the Finite Element analysis methods under development. The experimental programme uses a prototype test rig capable of applied simple shear to a square stiffened panel specimen. The rig applies simple shear by deforming the panel test area from a square section into a parallelogram section, Fig. 6. The rig actuator translates the loading beam above the specimen, initiating specimen deformation. The base beam, below the specimen, reacts the transverse specimen loading. Finally, the two side beams introduce complimentary shear loads and ensure the specimen parallelogram deformation. Each specimen is fixed into the rig using a series of angle section fixtures and high-strength shear bolts. 
The rig is a variation of a picture frame test rig with two of the four specimen corner pivot pins eliminated and rig-specimen flexible breather joints.

\subsection{Test Specimen Design and Manufacture}

Three test specimens were manufactured, each consisting of a $1.067 \mathrm{~m}$ by $1.067 \mathrm{~m}$ skin, stiffened by five bulb-tee section stringers and two c-section frame segments as shown in Fig. 7. This configuration gives one representative bay between the two frame segments, with the bays above and below this serving to introduce the loads into the structure and dissipate undesirable rig end condition effects. The selected specimen frame pitch of $356 \mathrm{~mm}$ is small when compared to typically midsize aircraft frame pitches, $400-500 \mathrm{~mm}$. The reduced pitch is designed to increase the diagonal-tension load in the stringers and decrease the load in the frames, hereby guaranteeing stringer failure before frame instabilities are encountered. The panel was designed such that the failure load was approximately three times the initial buckling load of the skin panels. The rivet pitch was chosen so as to eliminate inter-rivet buckling. The evaluated buckling load, using current empirical analysis methods, predicted local skin shear buckling at $71.24 \mathrm{kN}$ and stringer forced crippling failure at $293.44 \mathrm{kN}$.

The specimen skins were cut to size and a doubler bonded to each edge on both sides, of thickness $1.27 \mathrm{~mm}$, Fig. 7. The doublers were added to the design to ensure that any rig-specimen connection would not fail before specimen ultimate load. Due to the stiffness of the loading fixtures along with specimen doublers specimen end-shortening behaviour will potentially be limited. Doublers and skin were primed prior to hot bonding. The extruded bulb-tee stringers were bought as long 2024T311 sections. The extrusions were cut slightly over size, joggled to accommodate the skin doublers and heat treated to a T8511 temper. The oversized stringers along with the frames were riveted to the skin doubler assembly with $0.1563 \mathrm{~mm}(5 / 32 \mathrm{inch})$ diameter counter sunk rivets. The ends of the stringers were machined flush with the edges of the specimen. The frames were cut and rubber pressed from 7075 sheet in the annealed condition and subsequently heat treated to a T62 temper. 


\subsection{Specimen Tests}

Once manufactured each specimen underwent a skin surface scan to measure the initial skin geometry imperfection profile. The specimens were then marked, strain gauged and loaded into the $400 \mathrm{kN}$ capacity shear test rig. The specimens were loaded monotonically at a rate of approximately $20 \mathrm{kN} / \mathrm{min}$ with the displacement and strains recorded at approximately $10 \mathrm{kN}$ increments. Once the test was complete the specimen was removed and photographed.

\section{Results and Discussion}

\subsection{Model Meshes}

Based on the results of the mesh convergence study outlined in section 2, two baseline shear specimen models where built, one with second order elements, and one with first order elements. Fig. 8 illustrates the baseline second order specimen model. A mesh of 16 by 36 shell elements was required to model each skin bay and to accuracy represents stringer buckling behaviour four elements were used on each flange and web section. The first order mesh corresponded with the second order mesh, with four first order shell elements for every second order shell element and two first order beam elements for every second order beam element. All computational analysis results presented herein are based on the baseline first and second order meshes.

\subsection{Interface Idealisation}

The first phase of the modelling study examined sub-component interface idealisation, as contact between stringer flange and specimen skin and contact between frame flanges and specimen skin is an unresolved modelling issue for shear loaded panels. From each baseline model derivatives contact and non-contact models were generated. Fig.9 illustrates the sub-component interface idealisation for both the contact and non-contact models. For this first phase study each model simulated both tension and compression stress-strain behaviour based on the magnitude of compressive experimental material test data. 
For each of the four models, loading and boundary conditions were applied to replicate a simple shear deformation of the specimen. The prescribed model deformations transform the square specimen model into a parallelogram in order to simulate simple shear. This is experimental equivalent to having an infinitely stiff test rig and rig-specimen interface. The applied deformations resulting in a maximum deflection of the model upper edge nodes relative to the model lower edge nodes of $12.6 \mathrm{~mm}$. The simple shear loading arrangement restricts specimen end-shortening and will therefore limit collapse behaviour.

The first order non-contact model consisted of 80,131 element and 501,402 Degrees of Freedoms (DoFs), while the first order contact model consisted of 95,078 element and 546,243 DoFs. The second order non-contact model consisted of 23,170 element and 434,748 DoFs and the contact second order model consisted of 27,210 element and 446,868 DoFs. Table 1 presents the predicted maximum loads for each analysis model and details on analysis costs. In each case the maximum model load coincides with the maximum applied model deformation, indicating that the applied simple shear loading conditions limits specimen collapse behaviour.

All predicted maximum loads are within $3.2 \%$ for the lowest prediction of $403.1 \mathrm{kN}$, given by the first order non-contact model. Comparing the first order models, the contact model predicts a maximum load $0.35 \%$ higher than the non-contact model. The same pattern is repeated by the second order models with the contact model predicting a maximum load of $0.29 \%$ higher than the non-contact model. Examining the buckling behaviour, Fig. 10 presents the central skin and stringer deformation for all four models at maximum load. Clearly each model predicts the same skin and stringer buckling behaviour. It is worth noting the difference in load magnitude between the first order and second order models, with the second order models predict, on average $2.8 \%$, higher load magnitudes that the first order models. This shall be examined further in the second phase of the modelling study. 
Considering computational analysis costs, Table 1, the contact idealisation increases the number of model DOF therefore increasing the size of each analysis iteration. The contact idealisation also increases the number of required analysis iterations, roughly doubling the cost of the first order model specimen analysis. Considering the large increase in costs associated with contact analysis, one must assess if the gains in analysis accuracy outweigh the cost increases. With less than a $1 \%$ change in predicted maximum load between the contact and non-contact idealisations, the remaining modelling studies will focus on non-contact idealisations.

\subsection{Material Modelling}

As the work undertaken aims to benchmark computational analysis results against experimental results, actual specimen material properties are used in all computation models. Within the previous compression panel analysis work [16], material stress-strain data was based on the magnitude of compressive experimental material tests. However, since a shear loaded panel within its post buckling range will exhibit regions straining in tension and regions straining in compression, both tensile and compressive material behaviour must be considered. Six material coupons from each specimen component material batch were tested in order to determine average stress-strain curves for each type of material. Half the coupons were used to determine tensile properties and half used to determine compression properties. All tensile material tests were carried out in accordance with ASTM E8-93, and all compression tests were carried out in accordance with an in-house aerospace standard. The generated elastic-plastic stress-strain curves were averaged to produce the required input data for the Finite Element computational models.

Examination of both the compression and tension material data for the skin (2024-T3), stringer (2024-T8511) and the frame (7075-T62) indicates similar elastic behaviour in tension and compression, with major differences only occurring in the plastic range with the tension data indicating lower strain levels for given stress levels. Fig. 11, presents both the tension and compression material data for the specimen skin material, 2024-T3. 
The prior models, which examined interface idealisation, modelled both tensile and compressive stress-strain behaviour based on the magnitude of compressive experimental material tests. To examine material idealisation further derivative first and second order baseline non-contact models were generated based on the magnitude of tensile experimental material tests. In addition, in order to compare the computational results with the experiment test data the model loads and boundary conditions were modified to be as representative of the experimental test as possible. No longer modelling an infinitely stiff test rig but modelling the true rig stiffness and kinematics. The resulting load versus central skin bay shear strain curves obtained for the 'tension material' and 'compression material' models are shown in Fig. 12 together with the corresponding test data.

Examining the post buckling experimental specimen behaviour suggests that the stringer flanges are deformed due to the development of skin bay shear buckle waves, with the stringer flange waves then forcing the web and bulb structure to flex with the flange waves. This combination of skin buckles deforming stringer flange, and stringer web replicating flange waves is very much part of the mechanics of the forced crippling failure mode. However the specimen doublers and specimen-to-rig interface fixing angles limited the level of specimen end-shortening, therefore reducing the likelihood of specimen failure via forced crippling. Specimen loading in all cases resulted in permanent skin deformation; with all measured stringer strain values well below the stringer material's elastic limit. Experimental specimen failure may therefore be considered as permanent deformation of the skin and not stringer forced crippling due to the restriction of the experimental specimen boundary conditions.

Examining the shear strain response, Fig. 12, the first order models, second order models and experimental data exhibit similar strain-load response patterns. All have an initial high linear strain stiffness response, followed by a region of non-linear behaviour in which the high stiffness response reduces to a low stiffness response, followed by a relatively linear final stage of low strain stiffness response. 
For both the 'tension material' models and 'compression material' models the second order element models again predict higher stiffness response than the first order element models. Table 2 presents the predicted load for a critical strain level of 8000 microstrain. For the 'tension material' models the first order model predicts a critical load $2.7 \%$ lower that the second order model, and for the 'compression material' model the first order model predicts a critical load $2.8 \%$ lower that the second order model.

Considering material modelling all computational models predict shear strain behaviour which corresponds closely with experimental curves until the later stages of specimen loading. Clearly the selection of material data has a great effect on predicted behaviour within the later stages of the specimen post buckling analysis. Fig. 12 illustrates that for the shear specimen 'tension' material data predicts the upper bound and the 'compression' data generates the lower bound results. With respect to specimen critical strain load the 'tension material' models (both first and second order) predict a value $18 \%$ higher that the 'compression material' models. The derivation in predicted results is confined to the final stages of the specimen post buckling region when specimen strains reach plastic levels. Both the 'tension material' and 'compression material' models predict near identical local buckling loads and final skin and stringer deformation behaviour. Neither set of results will be $100 \%$ accurate as the specimen experiences both tension and compression behaviour, however analysing both cases will allow the definition of upper and lower behaviour boundaries. Current work is under way to develop and validate a stiffened panel shear buckling analysis with a 'tension-compression material' model (anisotropic material model).

Considering analysis costs, Table 2, the use of second order elements over first order elements reduces the model size, in terms of DOF, but does not reduce the required analysis computing time. Irrespective of model order this form of computational structural analysis is expensive in terms of hardware and analysis duration. 


\section{Conclusion}

\subsection{Conclusions}

The work presented herein contributes to the development of Finite Element methods for the accurate prediction of the post buckling behaviour of conventional aircraft fuselage panels subjected to varying combinations of loading. The work presented builds on the research carriedout by Lynch et al. [16], which focused on compression panel analysis. The presented work focused on flat riveted panels subjected to simple shear. Listed below are a series of guidelines for the Finite Element analysis of flat riveted panels subjected to shear. The guidelines are refined for the above structures only. Due to numerous factors affecting Finite Element predictions, it is necessary to carry out element / mesh / idealisation / imperfection / material / solution procedure studies relevant to the class of structure being studied.

$\underline{\text { Meshes }}$ - The shear panel mesh convergence study defined the need for a high-density skin mesh. More density is needed than that required for a similar geometry for compression panel analysis [16]. The reason for the high-density mesh is partly due to analysis constraints (rivet idealisation methods) and partly due to the panel post buckling shear wave patterns exhibiting smaller wavelengths than the compression post buckling patterns. With the same number of elements or nodes required per buckle half wave, the shear loaded panel therefore requires a higher mesh density. No general rules are suggested as to a minimum required mesh density as a full mesh convergence study is a fundamental component of any Finite Element analysis, particularly when considering instability.

Elements - First and second order elements were examined in order to assess their performance in modelling shear buckling structures. Analysis results revealed a small percentage difference in the post buckling stiffness predicted by the first and second order reduced integration element models, with the second order elements predicting a greater stiffness resulting in a $2.5 \%$ difference in predicted specimen load at the maximum applied experimental deflection. Although not a large 
deviation one would expect the reverse behaviour with the second order elements predicting a slightly lower stiffness.

Idealisation - An analysis study was undertaken to assess the merits of a contact sub-component interface idealisation over a non-contact idealisation. Analysis results revealed little difference in the predicted behaviour of contact and non-contact models, however the use of a contact idealisation increases analysis costs by at least $40 \%$ for the evaluation of a meter square panel. Based on these findings, contact sub-component interface idealisation is considered excessive for the structures under investigation. However, similar studies would be required if considering differing panel arrangements, particularly for stiffeners with a single row of attachment rivets.

Material modelling - It is obvious that the selection of material data is of great importance, with the incorrect definition of material data generating inaccurate analysis results. A shear loaded panel within its post buckling range will exhibit regions straining in tension and regions straining in compression, therefore analysis models must account for sub-component anisotropic material behaviour. Current work is under way to develop and validate a anisotropic material model.

\subsection{Future Work}

Future work is focused on the development and validation of anisotropic material model for use in shear panel buckling analysis. In addition, an experimental and computational programme is underway examining flat panels loaded in combined compression and shear loading. Subsequent phases will then consider applying the computational techniques to curved panel structures. In order to produce an analysis tool capable of modelling fuselage barrel behaviour, a systematic investigation is required on typical barrel imperfection forms and magnitudes and riveted panel initial stress imperfections. One proposed stream of research is the development of computational tools capable of modelling manufacturing processes in order to generate geometric and stress imperfections. 


\section{Acknowledgements}

The authors wish to thank the Industrial Research and Technology Unit (IRTU-ST-198) for their financial assistance, as well as Gary Moore, Ken Poston and Derek Cottney for their technical support.

\section{References}

1. Kuhn P. Stresses in Aircraft and shell structures, 1st edition, McGraw-Hill Book Co., 1956.

2. Wilson J M. On specifications for strength of iron bridges, Volume 15 Part I pp 401-403 489-490, Transactions of the American society of civil engineers, 1886.

3. Basler K. Strength of Plates Girders in Shear, Journal of the Structural Division, Proceeding of the American Society of Civil Engineers, Volume 87 pp 151-180, 1961.

4. Wagner H. Flat sheet metal girder with very thin metal web - PART I - General theories and assumptions, NACA-TM-604, NACA, 1931.

5. Kuhn P, Peterson J P, Levin L R. A summary of diagonal tension - PART I - Methods of analysis, NACA-TN-2661, 1952.

6. Kuhn P, Peterson J P, Levin L R. A summary of diagonal tension - PART II - Experimental evidence, NACA-TN-2662, 1952.

7. Bruhn E F. Analysis and Design of Flight Vehicle Structures. 1st edition, Tri-State Offset Company, 1973.

8. Wittenberg T C, van Baten J J, de Boer A. Design of fibre metal laminates shear panels for ultra-high capacity aircraft, Volume 4 pp 99-133, Aircraft Design, 2001.

9. Farley G L, Baker D J. In-plane shear test of thin panels, Volume 23 pp 81-88, Experimental Mechanics, 1983.

10. Sobel L, Sharp D. Comparison of analytical and experimental results for the post buckling behaviour of a stiffened, flat, composite shear panels, AIAA-94-1365-CP, 1994.

11. Singer J, Arbocz J, Weller T. Buckling experiments: Experimental methods in buckling of thin-walled structures, 1st edition, John Wiley \& Son, 1997. 
12. Levin L R, Sandlin C W. Strength analysis of stiffened thick beam webs, NACA-TN-1820, NACA, 1949.

13. Kuhn P, Peterson J P. Strength analysis of stiffened beam webs, NACA TN-1364, NACA, 1947.

14. Rothwell A, Liacos W J. Stiffened shear webs: Post buckling failure of stiffeners of less than critical rigidity, DES-8538, College of Aeronautics initial report, Cranfield institute of technology, July 1979.

15. Rothwell A. An experimental investigation of the post-buckling efficiency of Z-section stringer-skin panels, Volume 85 pp 29-33, Aeronautical journal, 1981.

16. Lynch C, Murphy A, Price M, Gibson A. The computational post buckling analysis of fuselage stiffened panels loaded in compression, Thin-Walled Structures, Vol. 42, No. 10, pp 1445-1464, 2004.

17. Domb M M, Elliott W G, Leigh B R. Modelling of stiffener Crippling Phenomena Using Finite Element Analysis. Canadian Aeronautics and Space Journal, Vol. 44, No. 4, pp 256$262,1998$.

18. Lynch C, and Sterling S G. A Finite Element Study of the Postbuckling Behaviour of a Flat Stiffened Panel. 21st ICAS Congress, Melbourne Australia, ICAS-98-7,7,3, 1998.

19. Apicella A, Armentani E, Cali C, Caputo F, Esposito R. Buckling and post buckling analysis of a GLARE thick flat side panel, Proceeding of ETCE/OMAE 2000 joint conference energy for the new millennium, New Orleans, US, 2000.

20. Anonymous. ABAQUS / Standard User's Manual. Version 6.1, Hibbitt, Karlsson and Sorenson, 2000.

21. Timoshenko S P, Gere J M. Theory of elastic stability, 2nd edition, McGraw-Hill Book Company Inc., 1961.

22. Bulson P S. The stability of flat plates, 1st edition, Chatto \& Windus, London, 1970.

23. Lynch C J. A Finite Element Study of the Post buckling Behaviour of a Typical Aircraft Fuselage Panel. PhD Thesis, Queen’s University Belfast, Belfast, N. Ireland, 2000. 
24. Hu S Z, Jiang L. A Finite Element simulation of the test procedure of stiffened panels, Volume 11 pp 75-99, Marine structures, 1998.

25. Baker D J, Kassapoglou C. Post buckled composite panels for helicopter fuselages: Design, analysis, fabrication and testing, Presented at the American Helicopter Society, Hampton roads chapter, structures specialists meeting, Williamsburg VA US, October 2001. 


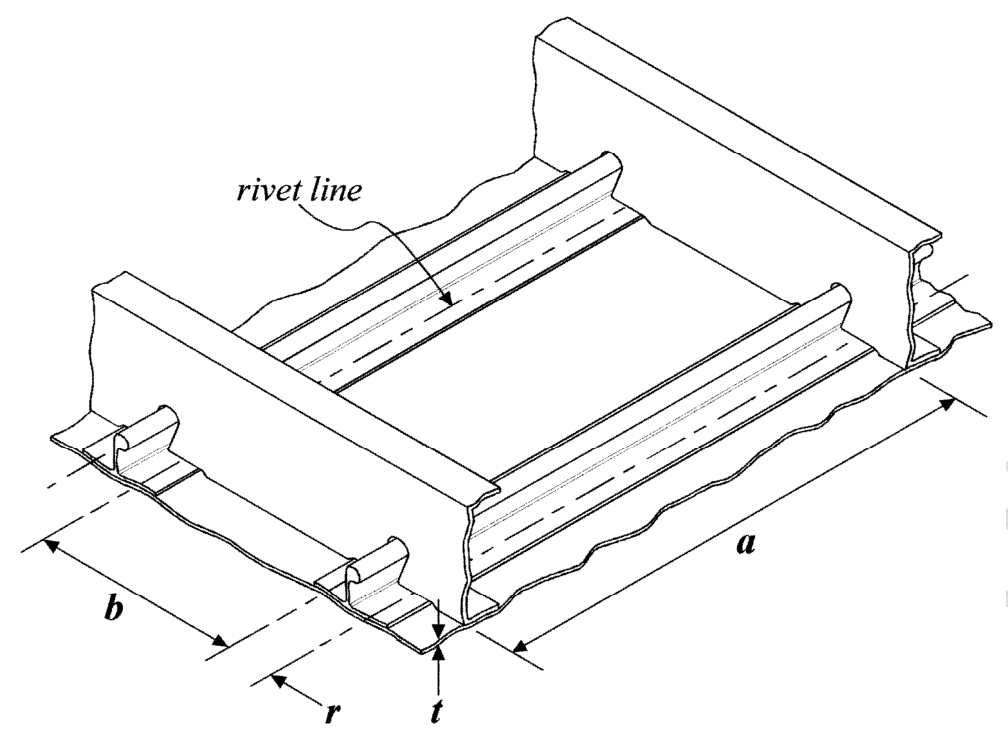

Fig. 1. Dimensions used to calculate local skin panel buckling stress.

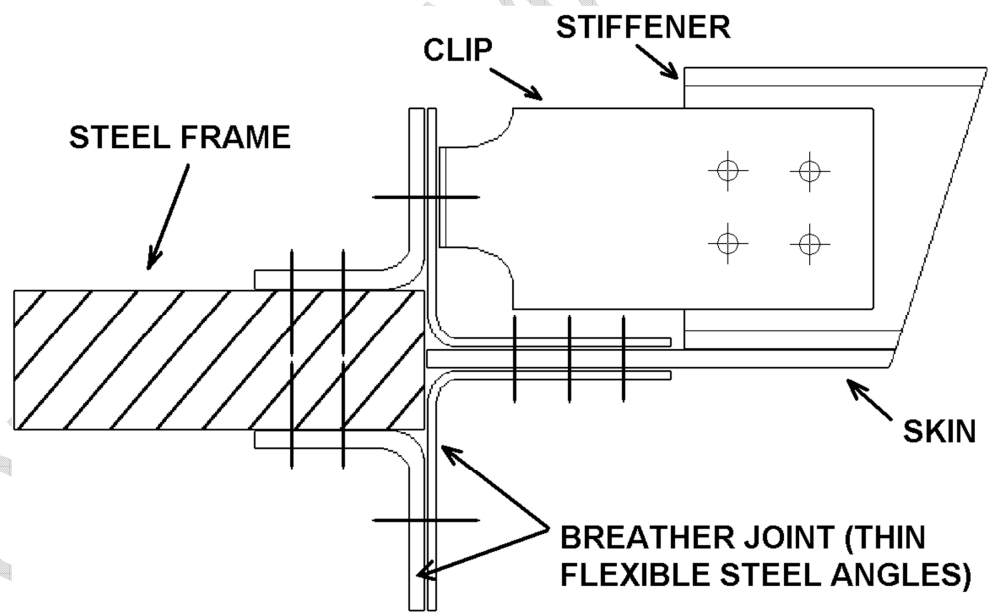

Fig. 2. Rig to specimen breather joint. 


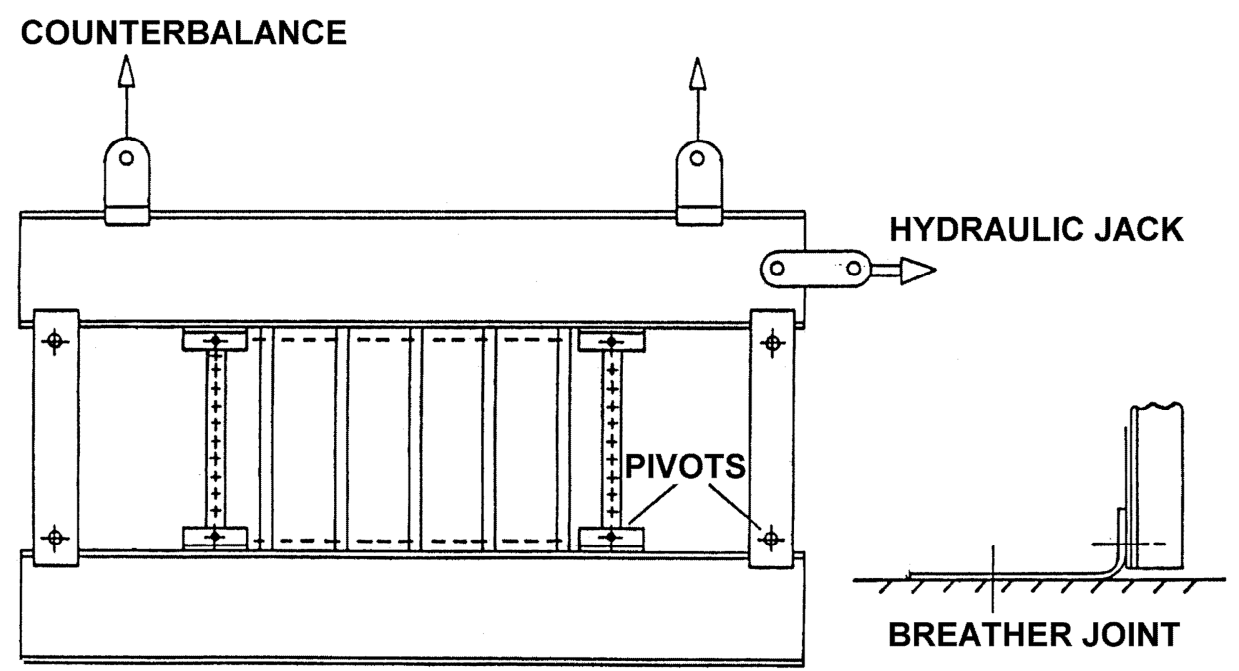

Fig. 3. Rothwell's rail shear rig [14].

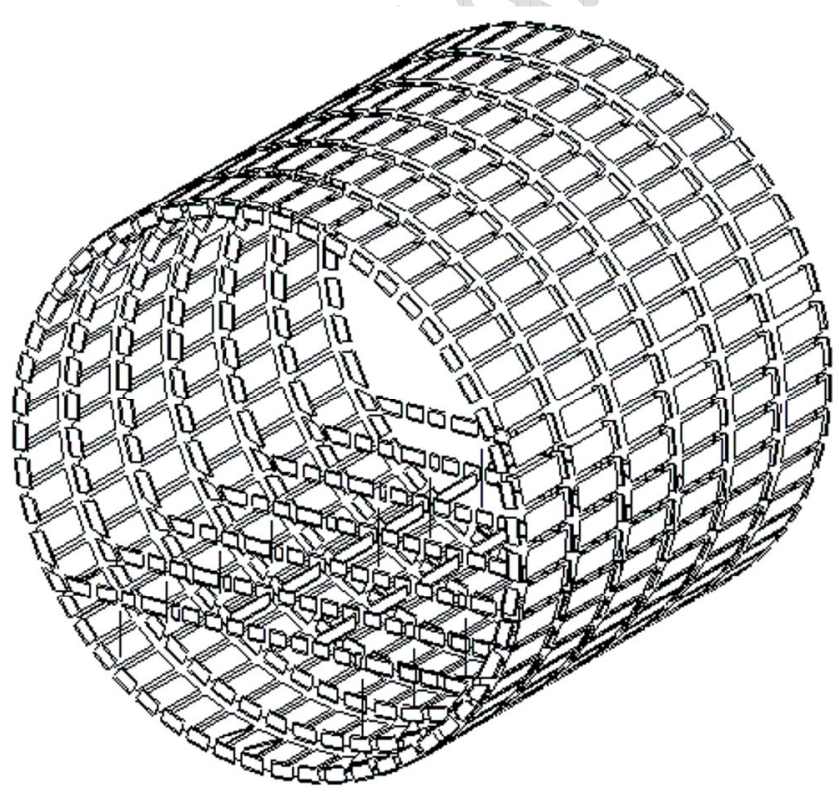

Fig. 4. Conventional stiffened panel idealisation. 


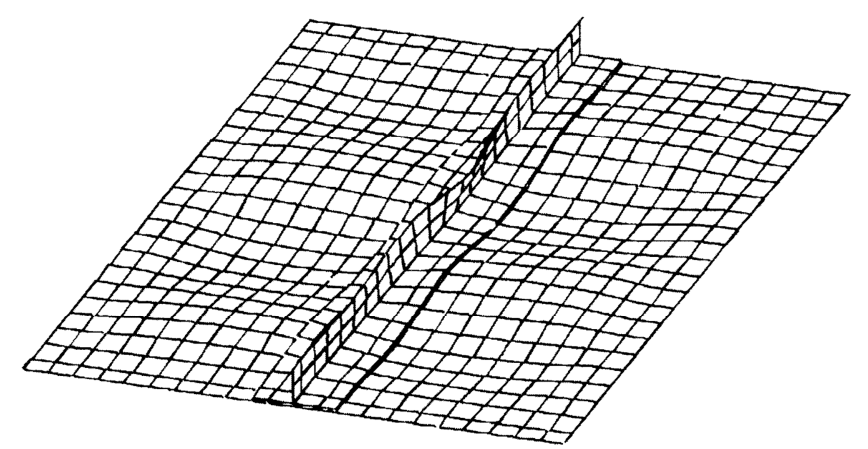

Fig. 5. 3D-shell skin-stringer idealisation.

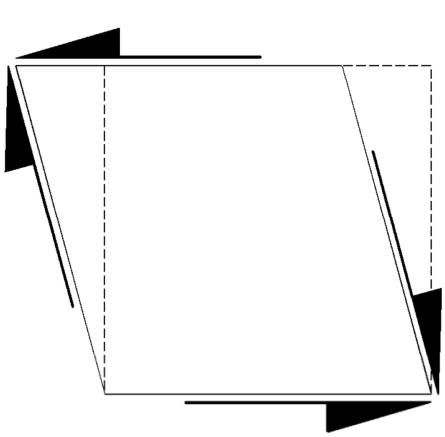

Simple Shear

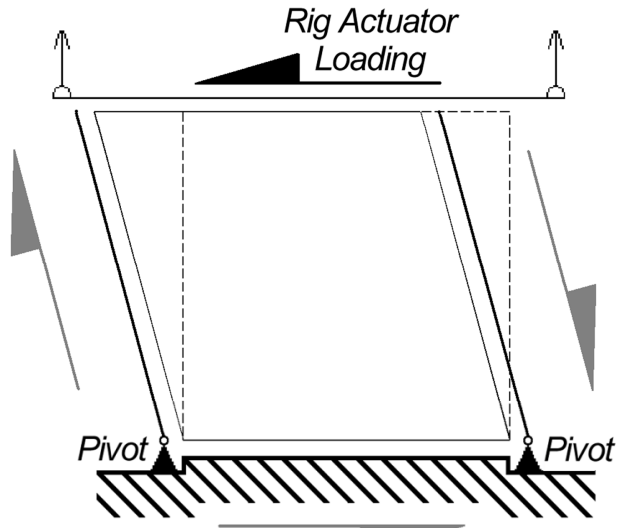

Shear Rig Schematic

Fig. 6. Shear rig schematic. 


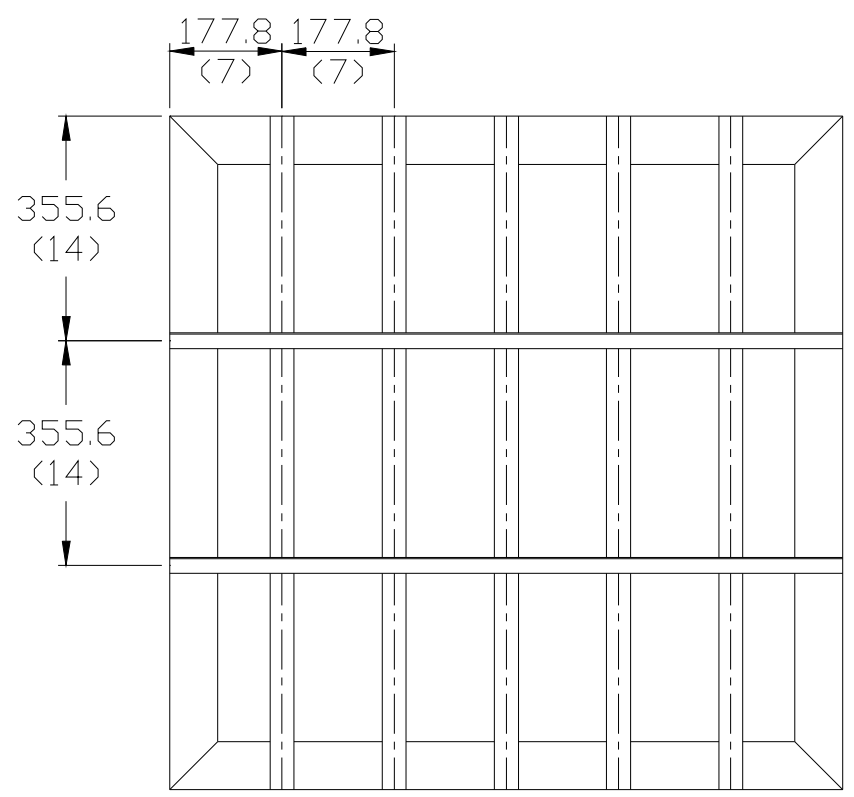

FRAME DIMENSIUNS STRINGER DIMENSIUNS
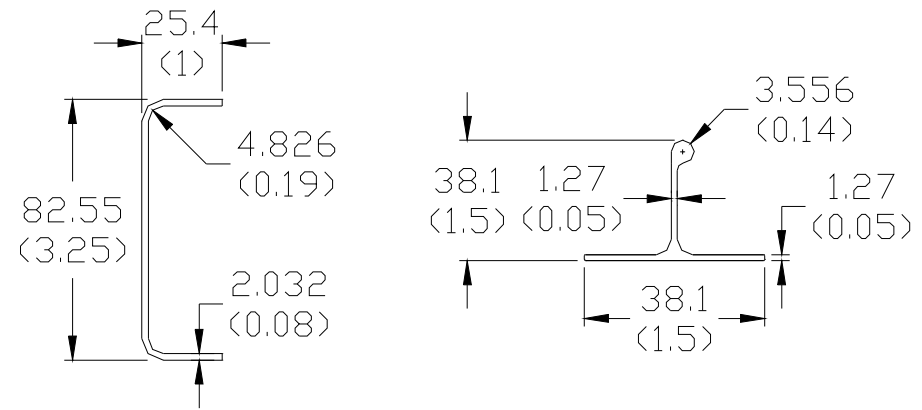

SKIN DOUBLER

\section{VDTES}

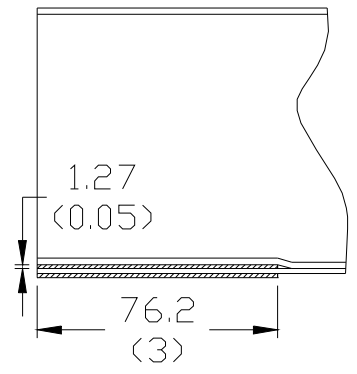

1) FRAME - 7075-T62

2) STRINGERS - 2024-T8511

3) $S K I N-2024-T 3$

3) SKIN TABS - 2024-T3

4) RIVETS - SULID,

100 CSK HEAD $\langle\phi 5 / 32\rangle$

ALL DIMENSIUNS IN MM 〈INCHES)

Fig. 7. Test specimen design. 


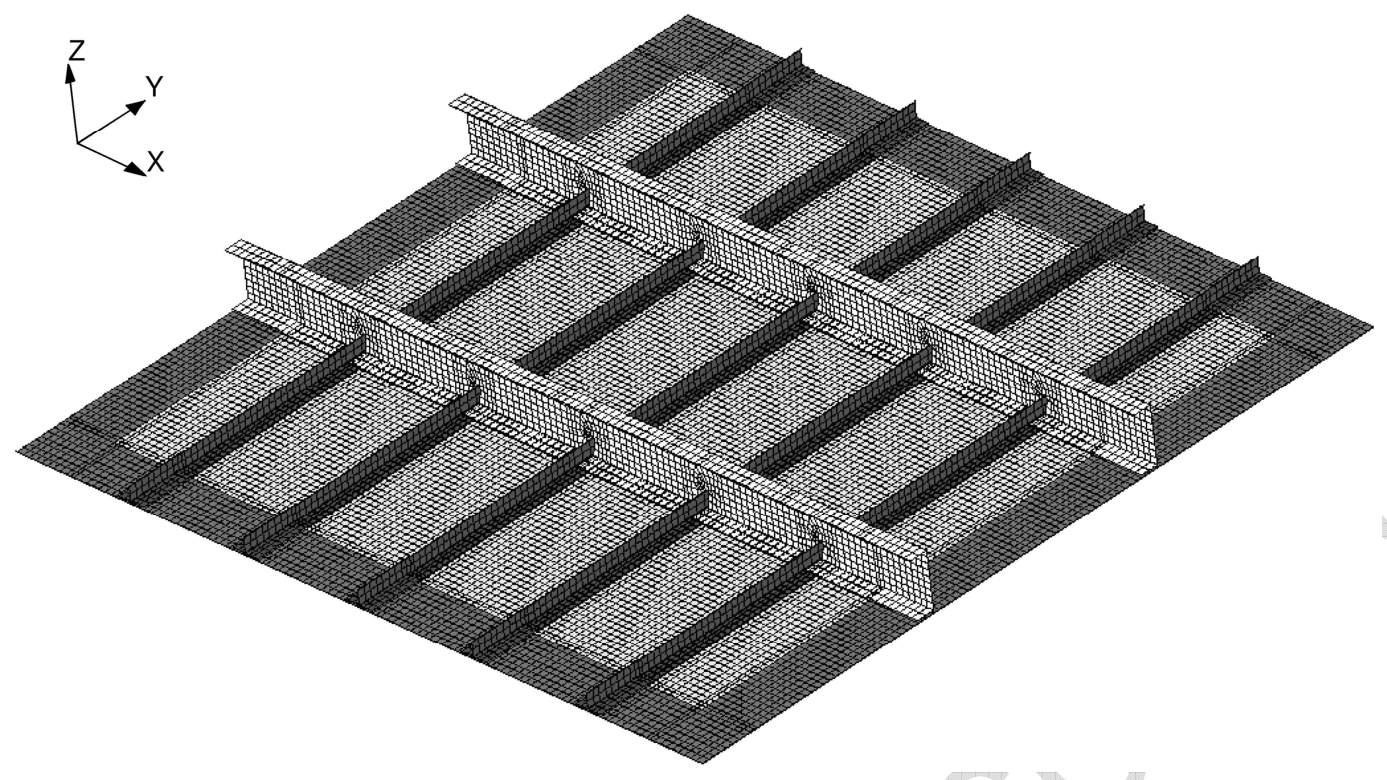

Fig. 8. Test specimen model (second order elements).

- Nodes

- - - Shell elements

I Rigid beams

[ Gap elements

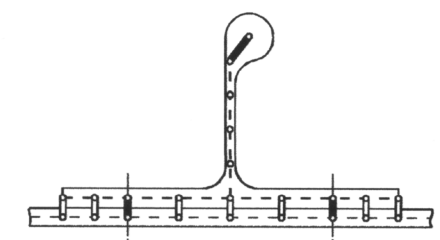

contact idealisation

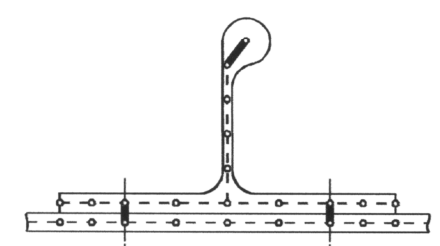

non-contact idealisation

Fig. 9. Skin-rivet-stringer interface idealisation. 


\section{First Order Models}
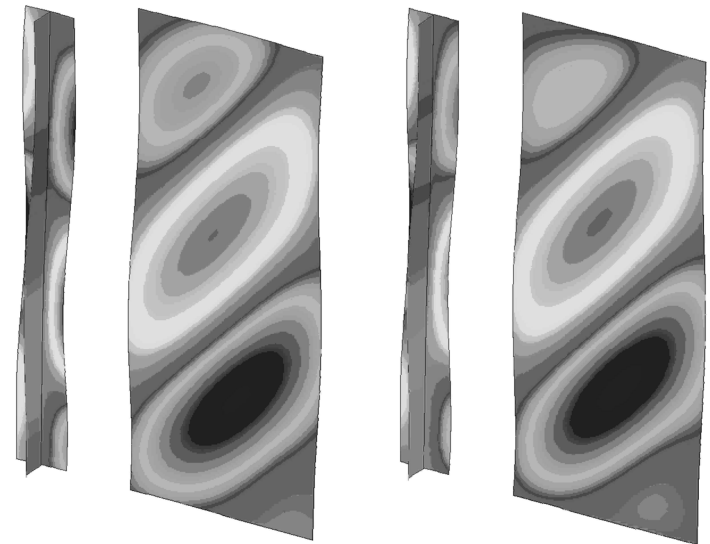

Non-contact Interface

Idealisation

Contact Interface

Idealisation

Second Order Models

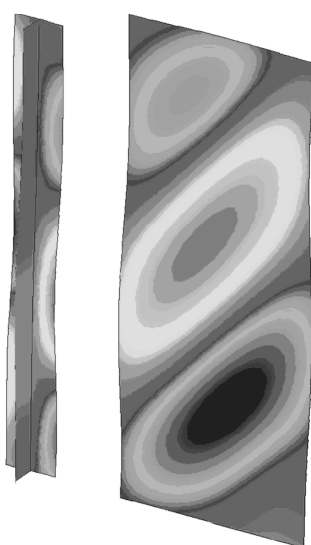

Non-contact Interface Idealisation

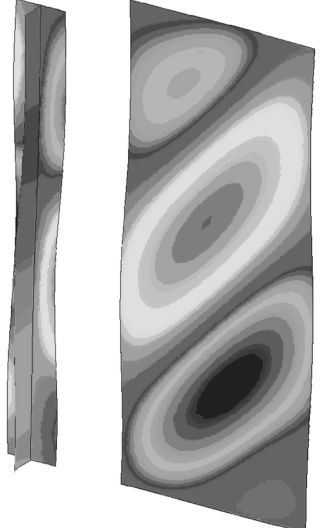

Contact Interface Idealisation

Fig. 10. Central skin and stringer deformation modes at maximum load level. 


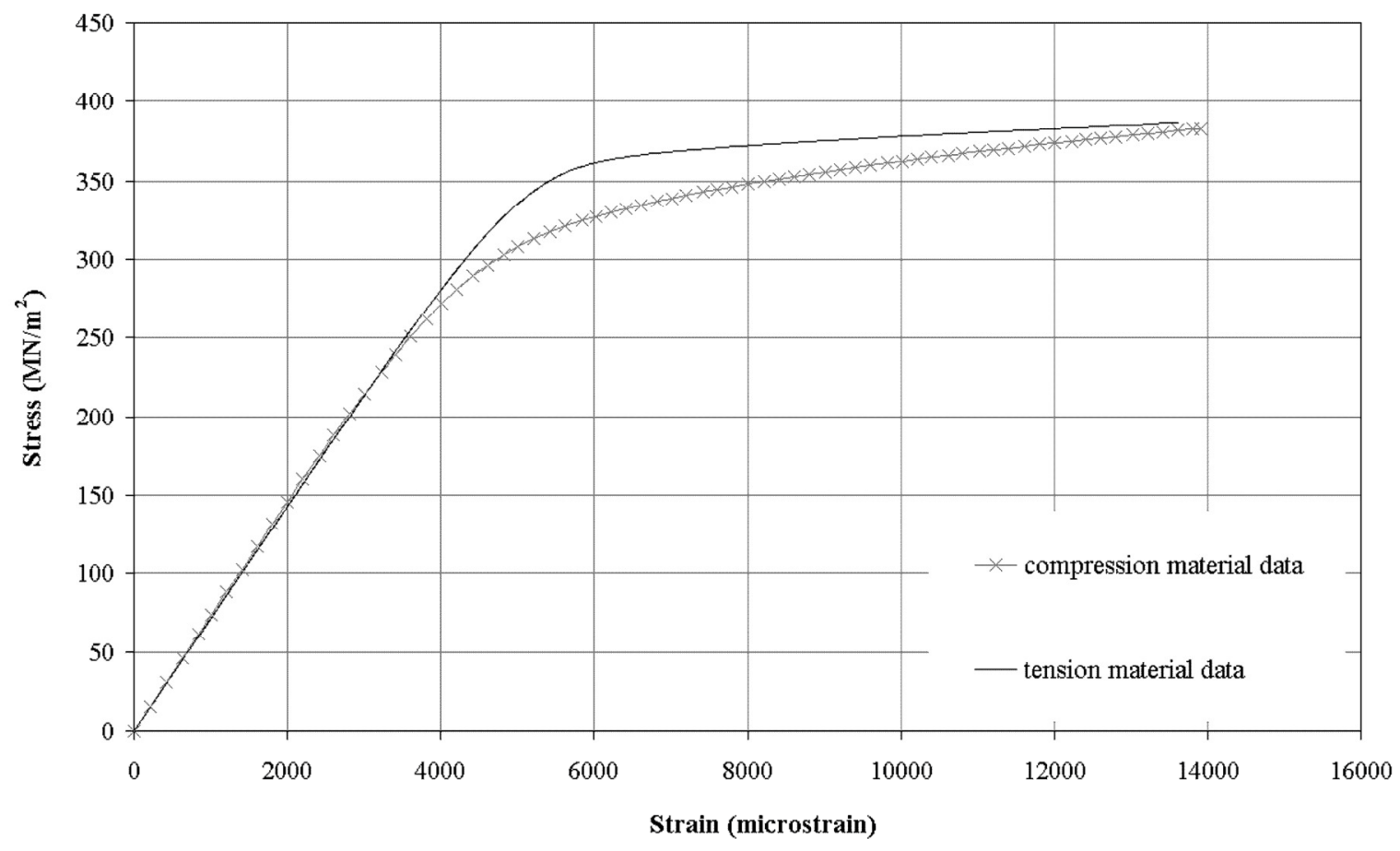

Fig. 11. Specimen skin material properties (2024-T3).

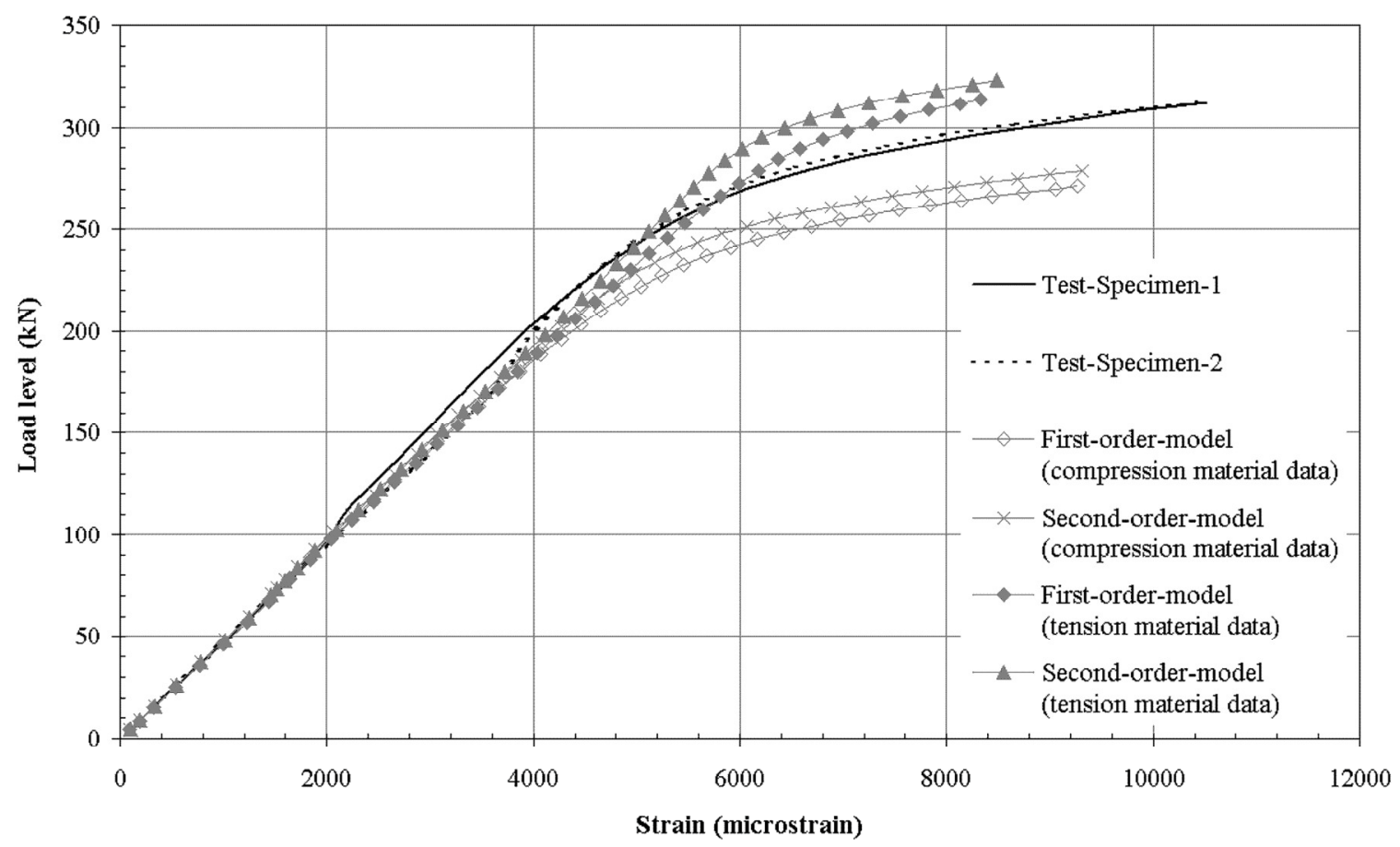

Fig. 12. Specimen experimental/computational load versus shear strain curves. 


\begin{tabular}{lccc}
\hline & $\begin{array}{c}\text { Maximum } \\
\text { Load } \\
(\mathbf{k N})\end{array}$ & $\begin{array}{c}\text { Number of } \\
\text { Analysis } \\
\text { Increments }\end{array}$ & $\begin{array}{c}\text { Number of } \\
\text { Analysis } \\
\text { Iterations }\end{array}$ \\
\hline $\mathbf{1}^{\text {st }}$ order model (non-contact modelling) & 403.1 & 63 & 196 \\
$\mathbf{2}^{\text {nd }}$ order model (non-contact modelling) & 414.9 & 54 & 168 \\
$\mathbf{1}^{\text {st }}$ order model (contact modelling) & 404.5 & 71 & 404 \\
$\mathbf{2}^{\text {nd }}$ order model (contact modelling) & 416.1 & 56 & 266 \\
\hline
\end{tabular}

Table. 1. Shear specimen contact modelling.

\begin{tabular}{lcccc}
\hline & $\begin{array}{c}\text { Critical } \\
\text { Strain } \\
\text { Level }(\mathbf{k N})\end{array}$ & $\begin{array}{c}\text { Percentage } \\
\text { Error* } \\
(\mathbf{\%})\end{array}$ & $\begin{array}{c}\text { Number of } \\
\text { Analysis } \\
\text { Increments }\end{array}$ & $\begin{array}{c}\text { Number of } \\
\text { Analysis } \\
\text { Iterations }\end{array}$ \\
\hline Test-Specimen-1 & $\mathbf{2 9 3 . 8}$ & --- & -- & --- \\
Test-Specimen-2 & $\mathbf{2 9 6 . 5}$ & --- & -- & -- \\
$\mathbf{1}^{\text {st }}$ order model (comp. mat. data) & 263.2 & -10.4 & 42 & 78 \\
$\mathbf{2}^{\text {nd }}$ order model (comp. mat. data) & 270.5 & -7.9 & 44 & 106 \\
$\mathbf{1}^{\text {st }}$ order model (ten. mat. data) & 310.6 & +5.7 & 42 & 81 \\
$\mathbf{2}^{\text {nd order model } \text { (ten. mat. data) }}$ & 319.4 & +8.7 & 44 & 103 \\
\hline$*$ - Based on lower bound test value (Test-Specimen-1) & & &
\end{tabular}

Table. 2. Shear specimen material modelling. 